\title{
Demographics and survival of AIDS cases with cancer, Washington, DC, 1996-2006
}

\author{
Heather A Young ${ }^{1}$, Eric Engels ${ }^{4}$, Ann-Marie Sufian-Kargbo ${ }^{1 \dagger}$, Alicia Vargas ${ }^{2}$, Kathleen Rogers ${ }^{2}$, Tiffany West ${ }^{3}$, \\ Amanda Castel $^{1^{*}}$ \\ From 13th International Conference on Malignancies in AIDS and Other Acquired Immunodeficiencies \\ (ICMAOI) \\ Bethesda, MD, USA. 7-8 November 2011
}

\section{Background}

Washington, DC (DC) has one of the highest HIV/AIDS rates in the U.S and cancer is the second leading cause of death among DC residents. This study sought to examine the demographic characteristics and survival of persons with AIDS defining cancers (ADCs) compared to those with non-AIDS defining cancers (NADCs) between the early HAART era (1996-2001) and the late HAART era (2002-2006) in DC.

\section{Methods}

Cases reported from 1996-2006 to the DC Cancer Registry and the AIDS Surveillance Registry were linked using a probabilistic matching algorithm. Cases were included if the cancer occurred from 4 months to 60 months postAIDS diagnosis and were stratified into ADCs and NADCs for analyses. Cancer diagnoses were stratified into the early and late HAART eras to compare the availability of HAART on the distribution of cancer type. KaplanMeier survival analysis and adjusted Cox proportional hazards regression were used to assess survival time and risk of death by cancer type.

\section{Results}

From 1996-2006, among 8,800 AIDS cases, 300 (3.4\%) cases had a cancer diagnosis. NADCs accounted for $51 \%$ of cancers and were significantly more likely to be diagnosed with AIDS $(\mathrm{p}<0.0001)$ and cancer $(\mathrm{p}<0.0001)$ at 40 years or older and had a significantly longer median time from AIDS to cancer diagnosis (2.46 vs. 1.75 years,

\footnotetext{
* Correspondence: sphaxc@gwumc.edu

+ Contributed equally

'Department of Epidemiology and Biostatistics, The George Washington University School of Public Health and Health Services, Washington, DC, USA Full list of author information is available at the end of the article
}

$\mathrm{p}=0.01)$ compared to ADCs. The most common ADCs were Kaposi sarcoma (40\%) and non-Hodgkin lymphoma (NHL) (44\%); the most common NADC cases were lung (20\%), Hodgkin lymphoma (8\%) and anal (8\%) cancer. ADCs accounted for $56 \%$ of cancer cases in the late-HAART as compared to the early-HAART period (45\%). Mortality within the first year of cancer diagnosis was similar (ADC $41 \%$ vs. NADC $37 \%$ ) and no statistical difference in survival time was observed. In the adjusted model, NHL and lung cases were significantly more likely to die as compared to other cancers (NHL HR=3.06; Lung HR=3.44).

\section{Conclusions}

In DC, despite high HIV/AIDS and cancer prevalence, only a small proportion of AIDS cases also develop cancer with ADCs and NADCs being equally common. HAART availability does not seem to have altered survival among ADCs and NADCs. Survival among NHL cases was relatively low reflecting the need for increased access to care among HIV+ persons. NADC cases are most likely developing cancers related to advancing age with higher proportions of lung cancers being observed. Public health efforts should focus on lung cancer prevention and continued monitoring of HIV-infected persons for cancers.

\footnotetext{
Acknowledgement

The authors would like to acknowledge the assistance of Drs. Aaron Adade, Joanne Lynn, Paul Levine, and Shannon Hader in the conduct of this study.

\section{Author details}

'Department of Epidemiology and Biostatistics, The George Washington University School of Public Health and Health Services, Washington, DC, USA ${ }^{2} \mathrm{DC}$ Cancer Registry, Community Health Administration, District of Columbia Department of Health, Washington, DC, USA. ${ }^{3}$ HIV/AIDS, Hepatitis, STD, TB Administration, District of Columbia Department of Health, Washington, DC, USA. Infections and Immunoepidemiology Branch, Division of Cancer
} 
Published: 19 April 2012

doi:10.1186/1750-9378-7-S1-P5

Cite this article as: Young et al:: Demographics and survival of AIDS

cases with cancer, Washington, DC, 1996-2006. Infectious Agents and

Cancer 2012 7(Suppl 1):P5.

Submit your next manuscript to BioMed Central and take full advantage of:

- Convenient online submission

- Thorough peer review

- No space constraints or color figure charges

- Immediate publication on acceptance

- Inclusion in PubMed, CAS, Scopus and Google Scholar

- Research which is freely available for redistribution

Submit your manuscript at 